\title{
Erratum to: Necessary Components for Lifestyle Modification Interventions to Reduce Diabetes Risk
}

\author{
Elizabeth M. Venditti • M. Kaye Kramer
}

Published online: 7 March 2012

(C) Springer Science+Business Media, LLC 2012

\section{Erratum to: Curr Diab Rep}

$$
\text { DOI 10.1007/s11892-012-0256-9 }
$$

The abovementioned article was published online first for the April 2012 issue of Current Diabetes Reports (volume 12 , issue 2).

On page 6, the following reference citation for Ackermann et al. [35] was incorrect:

Ackermann et al. [1] offered re-enrollment to their original YMCA DPP-treated group for an additional year of monthly contacts and found clinically significant weight losses of $6 \%$ among the $72 \%$ of original subjects who continued to participate in this extended phase.

The correct reference should be the following:

\section{Reference}

1. Ackermann RT, Finch EA, Caffrey HM, et al. Long-term effects of a community-based lifestyle intervention to prevent type 2 diabetes: the DEPLOY extension pilot study. Chron Illness. 2011;7(4):279-90.

The online version of the original article can be found at http://dx.doi. org/10.1007/s11892-012-0256-9.

E. M. Venditti $(\bowtie)$

Diabetes Prevention Program Outcomes Study,

Western Psychiatric Institute and Clinics,

University of Pittsburgh Medical Center,

3811 O'Hara Street,

Pittsburgh, PA 15213, USA

e-mail: vendittiem@upmc.edu

\section{K. Kramer}

Diabetes Prevention Support Center,

Graduate School of Public Health, University of Pittsburgh,

3512 Fifth Avenue, 3rd floor,

Pittsburgh, PA 15213, USA

e-mail: mkk3@pitt.edu 